\title{
VISUALIZATION OF ENZYME ACTIVITY IN GERMINATING CEREAL SEEDS USING A LIPASE SENSITIVE FLUOROCHROME
}

\author{
by \\ SVEND AAGE JENSEN and FLEMMING HELTVED \\ Department of Biotechnology, Carlsberg Research Laboratory \\ Gamle Carlsberg Vej 10, DK-2500 Copenhagen, Valby.
}

Keywords: Histochemistry, fluorescence, barley, wheat, rye, sorghum

The development patterns of hydrolytic enzymes during germination of barley, wheat, rye and sorghum were examined by a fluorescence staining technique. The method was based upon conversion of non-fluorescent fluorescein dibutyrate to highly fluorescent fluorescein, a reaction known to be preferentially catalyzed by lipase. The formation of hydrolases was compared with cell wall breakdown in germinating barley.

Fluorescence microscopy of longitudional sections of germinated cereal seeds revealed that a considerable amount of hydrolytic enzymes reacting with fluorescein dibutyrate was produced as germination proceeded. The initial formation site of the enzymes was found to be in the scutellum. Later in germination the hydrolases gradually diffused into the entire endosperm. The diffusion pattern of hydrolases in barley was found to coincide with cell wall breakdown. It is concluded that the fluorescein dibutyrate method has a potential as an indicator of the transport of de novo synthetized enzymes in cereal seeds. Practical applications of the fluorescein dibutyrate method are discussed.

\section{INTRODUCTION.}

The pattern of enzyme hydrolysis of the reserve substances in cereal seeds during germination have long been the object for extensive research. In spite of that, however, certain fundamental questions such as the role of scutellum contra the role of aleurone in the production of hydrolases at the onset of germination are still under discussion (14). In recent years, promising fluorescence techniques have been used to elucidate the pattern of $\alpha$-amylase formation (3) and cell wall breakdown (4) during ger- mination of barley. Using the substrate film technique (13), scanning electron microscopy (9) and transmission electron microscopy of sections and freeze fracture replicas $(5 a, 5 b)$ other research workers have come to the same conclusion as those working with the fluorescence techniques, i.e. that the scutellum plays a major role in the synthesis of hydrolytic enzymes during initial stages of germination. A review of some of these methods has recently been published (11).

The development of lipase (E.C.3.1.1.3.) during germination of cereal seeds has been the subject 
of several reports $(2,10,12,15,16)$. In the present study the development pattern of de novo synthesised hydrolases, presumably lipase, during germination of barley, wheat, rye and sorghum has been elucidated by the use of a simple fluorescence technique. The method involved conversion of non-fluorescent fluorescein dibutyrate to highly fluorescent fluorescein, a reaction previously reported to be catalized by various hydrolases but especially prominent by lipase $(6,7)$. For barley, a parallel study was carried out for the secretion into the endosperm of the hydrolases reacting with fluorescein dibutyrate and endosperm cell wall breakdown during germination.

\section{MATERIALS AND METHODS.}

\subsection{Plant material}

Seeds of barley (Hordeum vulgare cv. Nordal) harvested in 1977 were kindly supplied by S. Aastrup and K. ERdal, Department of Brewing Chemistry, Carlsberg Research Center. Seeds of wheat (Triticum vulgare cv. Solid) and of rye (Secale cereale cv. Petkus) were obtained from C.A. Qvade \& Co., Maribo, Denmark. Sorghum raw material (sorghum bicolor (L) Moench cv. Dabar) was kindly supplied by Dr. S. BADI, Food Research Institute, Khartoum, Sudan.

\subsection{Pilot malting}

Samples of barley, wheat and rye were micromalted according to a procedure previously described (1), at a germination temperature at 16 ${ }^{\circ} \mathrm{C}$. The sorghum sample was malted, essentially as described above. The temperature during germination was kept at $30^{\circ} \mathrm{C}$ for the first 24 hours followed by 3 days of germination at $21^{\circ} \mathrm{C}$.

All germinated samples were immediately frozen in liquid nitrogen and stored at $-20^{\circ} \mathrm{C}$ until use.

\subsection{Histochemical techniques}

\subsubsection{Visualization of cell wall breakdown}

Visualization of endosperm cell wall breakdown in germinated barley was based on the ability of Calcofluor (Polysciences Inc., Warrington, PA. U.S.A.) to stain intact endosperm cell walls of barley $(4,17)$. Individual kernels were sectioned into "half seeds" by a dorsoventral longitudinal cut. One of the "half seeds" was stained with Calcofluor according to the method de- scribed earlier (4) while the other was used for localization of hydrolases (see section 2.3.2).

\subsubsection{Visualization of hydrolases}

The method was based upon hydrolysis of nonfluorescent fluorescein dibutyrate to butyrate and highly fluorescent fluorescein ( $\lambda$ ex $=$ $490 \mathrm{~nm}$., $\lambda \mathrm{em}=520 \mathrm{~nm}$.), catalyzed by hydrolases, especially lipase $(6,7)$. Fluorescein dibutyrate was obtained from Serva Feinbiochemica (Heidelberg, West Germany). Individual halved kernels (see section 2.3.1), were stained at room temperature with a $\mathrm{I} \times 10^{-3} \mathrm{M}$ solution of fluorescein dibutyrate in $80 \% \mathrm{v} / \mathrm{v}$ aqueous ethanol. It was also found that the seed fixation system recently reported by HeLTVED et al. (8) could be conveniently used to obtain 50 "half seeds" in one working operation on a Cernit-plate.

\subsection{Fluorescence microscopy}

The Calcofluor and fluorescein dibutyrate stained "half seeds" were examined in a Reichert Univar microscope (Reichert, Austria) using a plan $2.5 \mathrm{x}$ objective. Excitation and emission filters were custom made by Optisk Laboratorium (Lyngby, Denmark) and had the following characteristics: Calcofluor fluorescence - short wave pass SWP $400 \mathrm{~nm}$ exciter and long wave pass LWP $418 \mathrm{~nm}$ emission filter; Fluorescein fluorescence - Band Pass BP 455-490 nm exciter and long wave pass LWP $515 \mathrm{~nm}$ emission filter. All photomicrographs were taken on Kodak Ektachrome 400 film.

\section{RESULTS}

\subsection{Localization of hydrolases in germinating barley seeds}

The pattern of hydrolase development and cell wall breakdown in germinating barley seeds were followed with time by examining longitudinal sections (Figure 1). The ungerminated barley seeds stained with fluorescein dibutyrate showed only trace of fluorescence. Even the embryo part of the barley kernel lacked fluorescence thus demonstrating a low level of activity for enzymes hydrolysing fluorescein dibutyrate. The corresponding "half seed" stained with Calcofluor showed intact endosperm cell walls adjacent to the scutellum and in the rest of the endosperm. After one day of germination a weak yellow fluo- 
rescence appeared in the scutellum of the kernel indicating that induction of enzymes had occurred at this stage of germination. In barley kernels that have been incubated for three days a distinct yellow fluorescence appeared at the scutellum endosperm interface. The configuration of the modified area as visualized by the fluorescein test coincides well with the the cell wall breakdown indicating similar diffusion pattern of the enzymes in question and the cell wall degrading enzymes, including $\beta$-glucanase.

The following study of appearance of hydrolases and cell wall breakdown in barley seeds which had been incubated in water for 5,7 and 10 days, (Figure 1) clearly confirmed that the diffusion of hydrolases into the endosperm proceeded in similar way to that observed for cell wall breakdown. After 5 days of germination about $40 \%$ of the barley endosperm appears modified, after 7 days about $75 \%$ and finally after 10 days of germination the whole endosperm was observed to be modified.

In order to confirm the enzymic nature of fluorescein dibutyrate degradation, a barley kernel germinated for 6 days was boiled in water for 10 min followed by staining the two "half seeds" with: 1) fluorescein dibutyrate and 2) Calcofluor. The "half seed" stained with fluorescein dibutyrate (Figure I) showed no distinct yellow fluorescence in the endosperm in accordance with the expectation of a heat inactivation of the enzymes hydrolysing fluorescein dibutyrate. In contrast, Calcofluor bound to the residual intact cell walls of the endosperm thus visualizing the unmodified area of the endosperm. In the embryo, however, there appears to be an increased yellow fluorescence also in the heated kernel as compared with the ungerminated control, indicating a more heat stable fluorescein dibutyrate splitting activity in this tissue.

\subsection{Localization of hydrolases in germinating wheat, rye and sorghum seeds}

Examination of ungerminated seeds of wheat rye and sorghum stained with fluorescein dibutyrate showed no significant yellow fluorescence in the endosperm (Figure 2), in accordance with the observations for barley (Figure 1). After one day of germination both wheat and sorghum showed a distinct yellow fluorescence in the scutellar tissue. The fluorescence seen with sorghum was very pronounced. With respect to sorghum, however, it must be emphasized that the germination temperature was kept at $30^{\circ} \mathrm{C}$ for the first 24 hours as compared to $16{ }^{\circ} \mathrm{C}$ for barley, wheat and rye. The rye kernel incubated for one day showed only a slight fluorescence. In the 2 days sections, all three cereal seeds exhibited a distinct yellow fluorescence in the endosperm. In half seeds of wheat, rye and sorghum malted for more than 2 days, hydrolytic activity gradually spread over the entire endosperm as germination proceeded in a pattern similar to that observed for barley.

\section{DISCUSSION}

It has been reported (7) that hydrolysis of fluorescein dibutyrate by lipase (porcine pancreas, steapsin and wheat germ lipase) occur specifically unaffected by the presence of other esterases (cholinesterase and acetylcholinesterase). In the same study, however, it was found that both acylase and chymotrypsin hydrolyse fluorescein dibutyrate at a lower rate. An activity of acylase and chymotrypsin-like enzymes in cereal seeds may therefore also be responsible for hydrolysis of fluorescein dibutyrate. Further investigations of the enzymic nature of fluorescein dibutyrate hydrolysis is required but because of the very high affinity of lipase to this particular substrate, we favour lipase as the primary candidate. Considering wheat, our results agree well with a previous study (15), in which de novo synthesized lipase has been extracted by ice-cold acetone and determined by a titrimetric method using maize germ oil as substrate. It was shown that lipase activity appeared in the starchy endosperm within 12 hours of incubation and culminated with a fifty-fold increase after 6 days of incubation. For barley, similar investigations employing water extraction of lipase $(10,12)$ suggested only a twofold increase in lipase during the course of germination, which would be difficult to reconcile with the present results, if the fluorescein dibutyrate indeed is hydrolyzed by lipase. In one of these studies (10) it was pointed out that not more than $15 \%$ of the lipase could be extracted with water from the grain before germination or during malting and thus the apparent differences may be due to inadequate extraction procedure. 


\section{BARLEY}

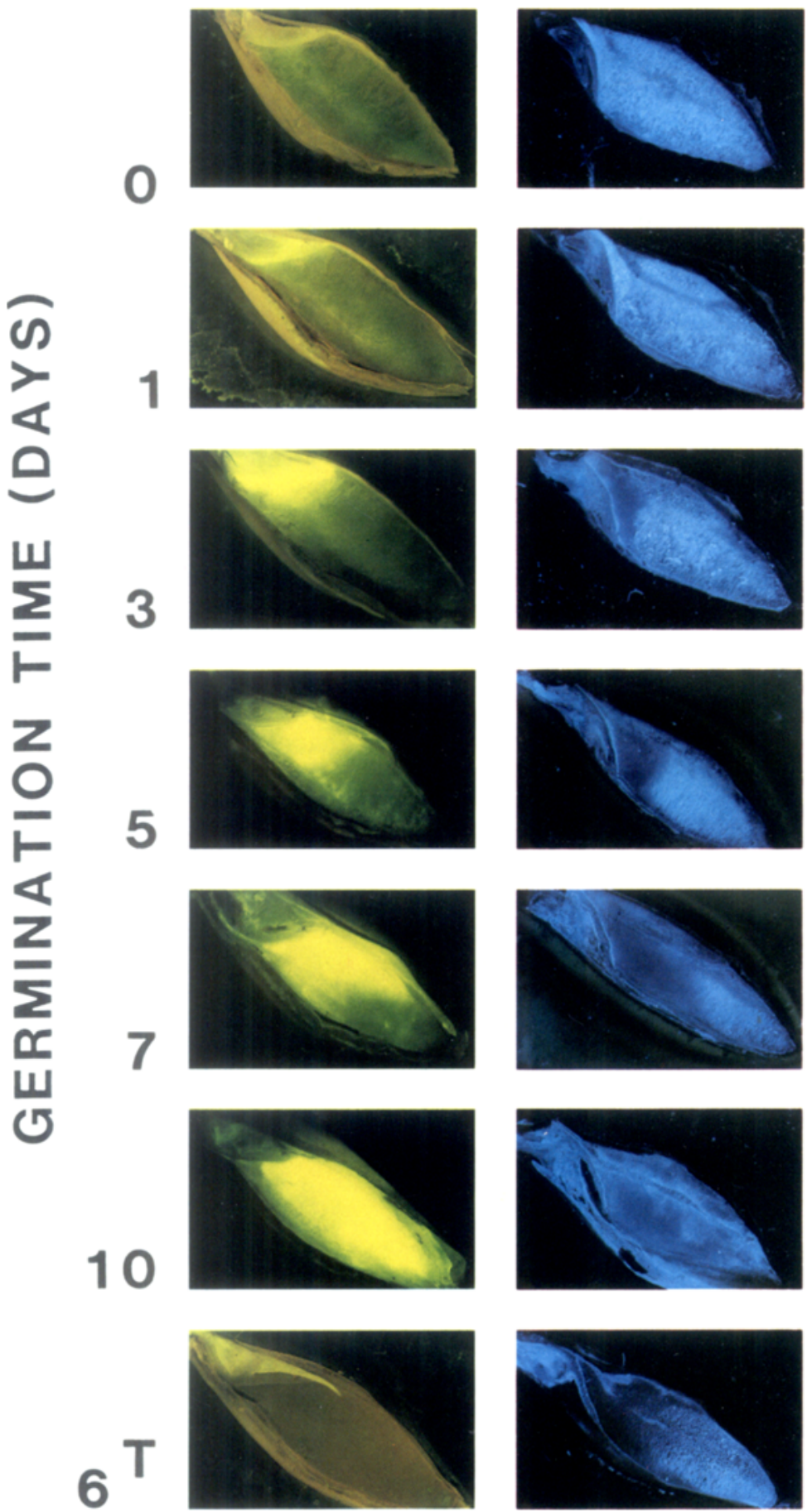

Figure l. Formation of activity of enzymes catalysing the hydrolysis of fluorescein dibutyrate into fluorescein (left) and progression of cell wall breakdown (right) in germinating barley seeds. Longitudinal sections were treated with fluorescein dibutyrate and Calcofluor, respectively.

$\mathrm{T}=$ Barley seed, $(6$ days of germination) boiled in water for $10 \mathrm{~min}$ prior to staining. 
S. Aa. Jensen \& F. Heltved: Localization of hydrolases

WHEAT
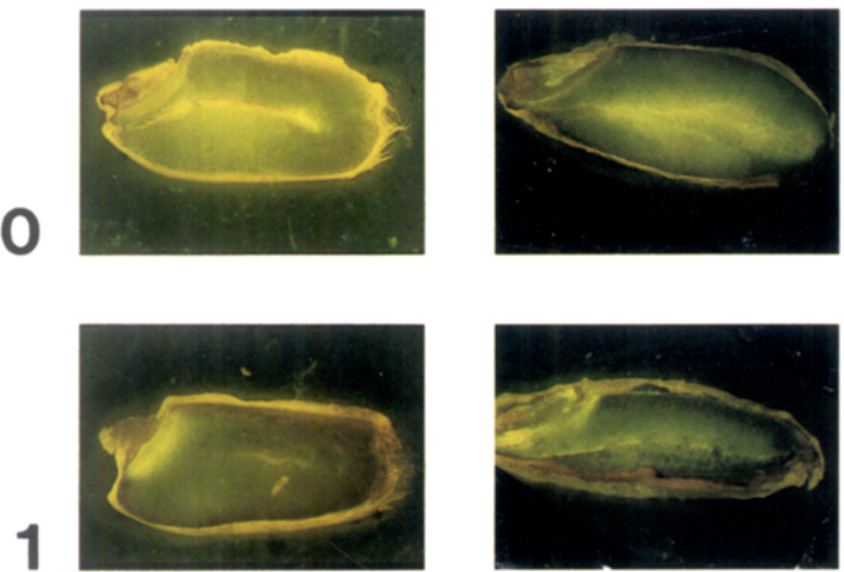

$\frac{5}{3}$

U.

$\Sigma$

$\overline{1}$

$\frac{2}{2}$

$\frac{2}{2}$

3

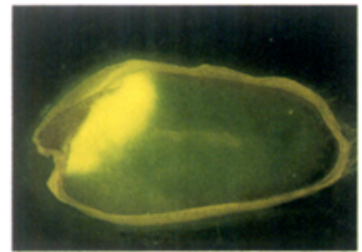

2
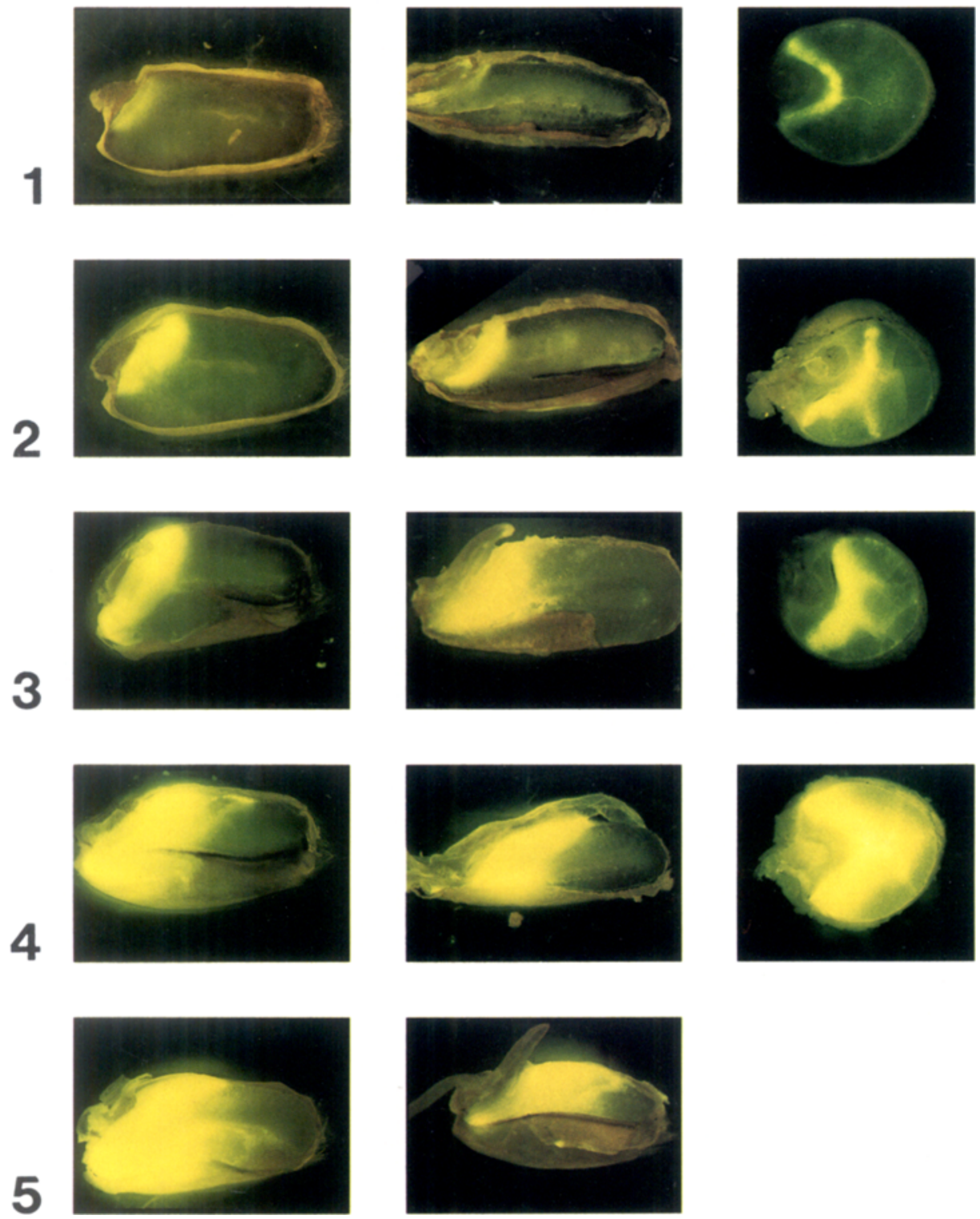

SORGHUM
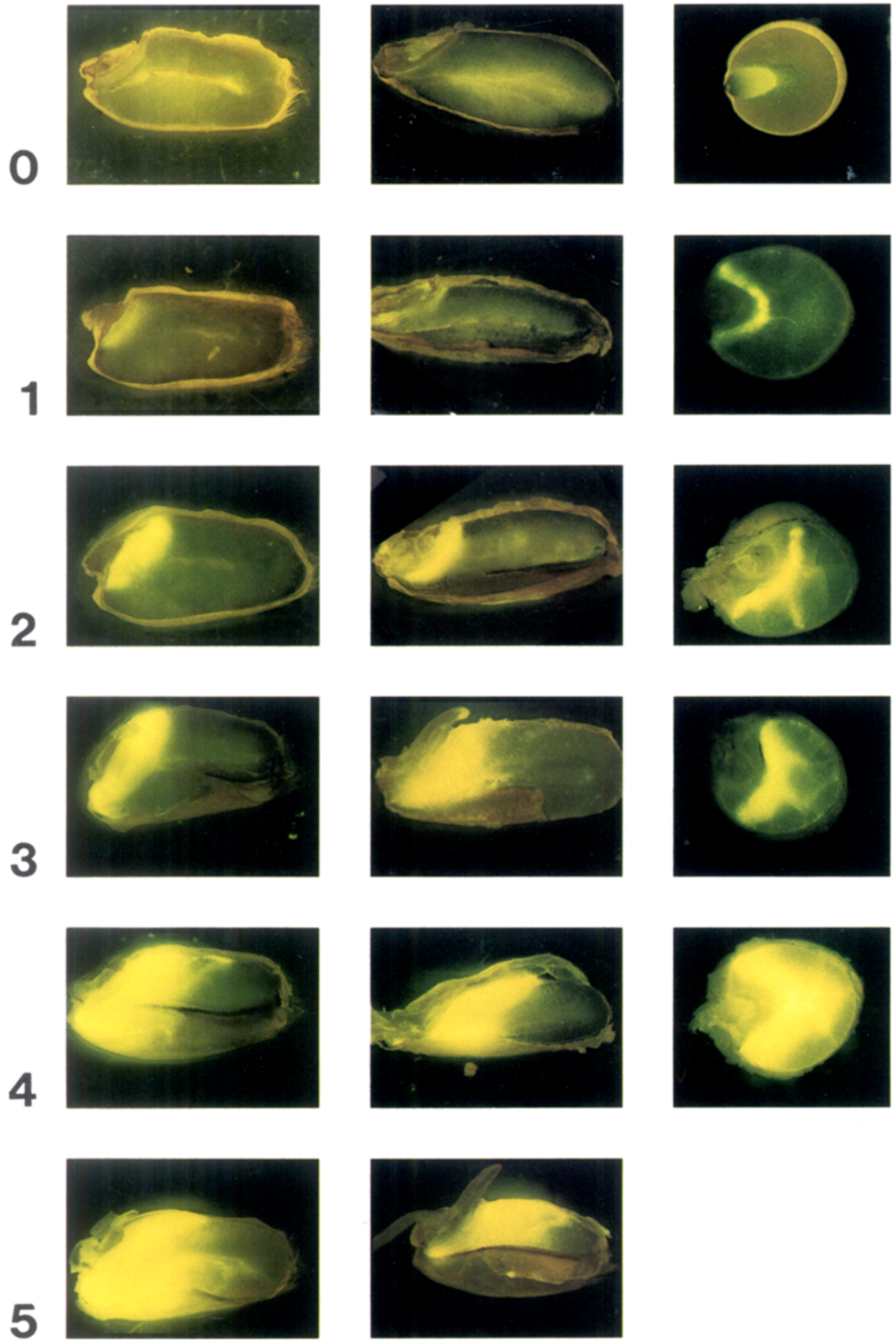

Figure 2. Progressive appearance of hydrolases in germinating wheat, rye and sorghum seeds as seen in sections treated with fluorescein dibutyrate. 
The development pattern of hydrolytic activity in all four cereals demonstrates that in the early stage of germination, the activity appeared invariably and symmetrically in the scutellum and later gradually diffused into the distal region of the endosperm. These findings of the initial site and diffusion pattern of the hydrolytic activity in germinating cereal grains are consistent with previous reports on the distribution of $\alpha$-amylase $(3,9,13)$, protease and ribonuclease (13) during malting as well as with the pattern of cell wall breakdown (4) and starch grain degradation $(5 a, 5 b, 9)$.

The parallel development of hydrolytic activity and cell wall breakdown in germinating barley is also coincident with the development of $\alpha$ amylase activity (4). On the basis of these conclusions and the fact that the development pattern of hydrolytic activity in wheat, rye and sorghum are similar to that of barley, the fluorescein dibutyrate method constitutes an alternative general indicator for sprouting in barley, wheat, rye and sorghum. The method's practical application requires, however, that the hydrolytic activity as determined by fluorescein dibutyrate survives drying the seeds. Preliminary investigations have shown that hydrolytic activity in barley is retained after $30 \mathrm{~min}$ of drying at temperature as high as $70^{\circ} \mathrm{C}$.

\section{ACKNOWLEDGEMENTS}

The authors wish to thank Dr. L. MUNCK and Dr. G. GibBons for critical review of the manuscript. The help of Ms. BRITHA JENSEN in typing the manuscript and of Ms. Ulla-Karin GibBons for preparing the figures is also greatly acknowledged.

\section{REFERENCES}

1. Aastrup, S. \& K. Erdal: Quantitative determination of endosperm modification and its relationship to the content of 1,3:1,4- $\beta$-glucans during malting of barley. Carlsberg Res. Commun. 45, 369-379 (1980)

2. Drapron, R., N. Anh, B. Launay \& A. GuILBOT: Development and distribution of wheat lipase activity during the course of germination. Cereal Chem. 46, 647-655 (1969)
3. GibBons, G.C.: On the localisation and transport of $\alpha$-amylase during germination and early seedling growth of Hordeum vulgare. CarIsberg Res. Commun. 44, 353-366 (1979)

4. GibBons, G.C.: On the sequential determination of $\alpha$-amylase transport and cell wall breakdown in germinating seeds of Hordeum vulgare. Carlsberg Res. Commun. 45, 177-184 (1980)

5a. GRAM, N.H.: The ultrastructure of germinating barley seeds I. Changes in the scutellum and the aleurone layer in Nordal barley. Carlsberg Res. Commun. 47, 143-162 (1982)

5b. Gram, N.H.: The ultrastructure of germinating barley seeds II. Breakdown of starch granules and cell walls of the endosperm in three barley varieties. Carlsberg Res. Commun. 47, 173-186 (1982)

6. Guilbault, G.G. \& J. Hiesenman: Fluorometric substate for sulfatase and lipase. Anal. Chem. 4l, 2006-2009 (1969)

7. Guilbault, G.G. \& D.N. Kramer: Fluorometric determination of lipase, acylase, alfaand gamma-chymotrypsin and inhibitors of these enzymes. Anal. Chem. 36, 409-412 (1964)

8. Heltved, F., S. Aastrup, O. Jensen, G. GibBONS \& L. MUNCK: Preparation of seeds for mass screening. Carlsberg Res. Commun. 47, 291-296 (1982)

9. MacGregor, A.W. \& R.R. Matsuo: Starch degradation in endosperm of barley and wheat kernels during initial stages of germination. Cereal Chem. 59, 210-216 (1982)

10. MacLeod, A.M. \& H.B. White: Lipid metabolism in germinating barley II. Barley lipase. J. Inst. Brew. 68, 487-495 (1962)

11. Munck, L., G. Gibbons \& S. Aastrup: Chemical and structural changes during malting. Proceedings of European Brewery Convention, Copenhagen, Il-30 (1981)

12. Narziss, L. \& Y. Sekin: Über das Verhalten der Lipase während des Mälzungs- und Brauprozesses. Brauwissenschaft 27, 3ll-320 (1974)

13. Okamoto, K, H. Kitano \& T. Akazawa: Biosynthesis and excretion of hydrolases in germinating cereal seeds. Plant and Cell Physiology. 21, 20l-204 (1980).

14. PALMER, G.H.: A reassessment of the pattern of endosperm hydrolysis (modification) in germinated barley. J. Inst. Brew. 88, 145-153 (1982)

15. TAvener, R.J.A. \& D.L. Laidman: The induction of lipase activity in the germinating wheat grain. Phytochemistry ll, 981-987 (1972) 
16. WAINWRIGHT, T.: Effect of barley and malt lipids on beer properties. Proceedings of European Brewery Convention, Symposium on Malt and Beer, Helsinki, 118-128 (1980)
17. WoOD, P.J. \& R.G. FulcheR: Interaction of some dyes with cereal $\beta$-glucans. Cereal Chem. $55,952-966(1978)$ 